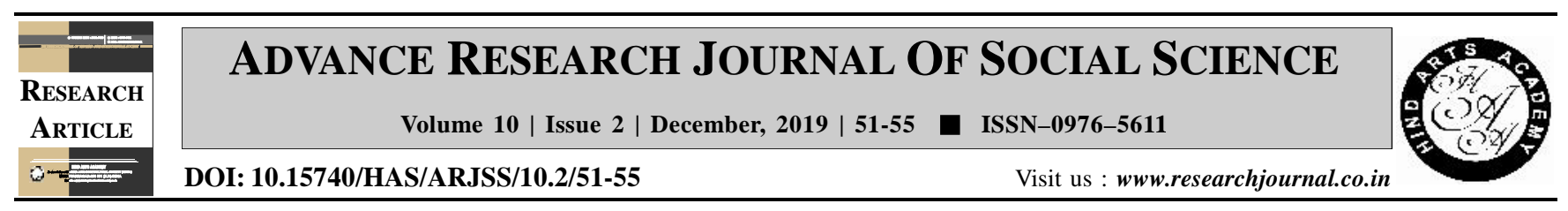

\title{
Pre and post-natal care: A study on knowledge level of young rural mothers
}

Krishna Baruah*, Jinamoni Saikia and Bondipa Dutta

Department of Human Development and Family Studies, College of Community Science, Assam Agricultural University, Jorhat (Assam) India

(Email : kiki_barua@yahoo.co.in)

\section{ARTICLE INFO :}

$\begin{array}{lll}\text { Received } & : & 09.07 .2019 \\ \text { Revised } & : & 05.11 .2019 \\ \text { Accepted } & : & 21.11 .2019\end{array}$

KEY WORDS :

Adolescent marriage, Rural mothers

HOW TO CITE THIS ARTICLE :

Baruah, Krishna, Saikia, Jinamoni and Dutta, Bondipa (2019).Pre and post-natal care: A study on knowledge level of young rural mothers. Adv. Res. J. Soc. Sci., 10 (2): 51-55, DOI: 10.15740/HAS/ARJSS/ 10.2/51-55. Copyright@2019: Hind Agri -Horticultural Society

*Author for correspondence

\begin{abstract}
The present study pre and post-natal care: A study on knowledge level of young rural mothers' was carried out in Jorhat district of Assam with the objectives to assess the knowledge level of rural women on pre and post-natal care and to study the knowledge of mothers about health, hygiene and nutrition. A total of eleven villages were selected randomly from Jorhat district for the study. The study was conducted among 325 young rural mothers having children below 6 years of age. The assessment was done with the help of a standardized questionnaire developed by AICRP-CD component. This tool consisted of 45 numbers of items measuring three different areas namely health, hygiene and nutrition. The findings revealed that majority (83.69\%) of respondents had good knowledge regarding maternal health. While considering the three areas separately, knowledge level of all the respondents was found to be good, but still they lack in practicing their knowledge in certain aspects. Likewise more than half of the respondents were not aware that weight gain and numbness of feet are the part of pregnancy. As many as 33.23 per cent of respondents still believe that a child who suffers from diarrhea should not be given good amount of liquid. Likewise respondents $(45.85 \%)$ still believe that a child should not breastfed during his or her illness. Only 64 per cent of respondents believe that a child should be given variety of foods to supplement the balance diet.
\end{abstract}

